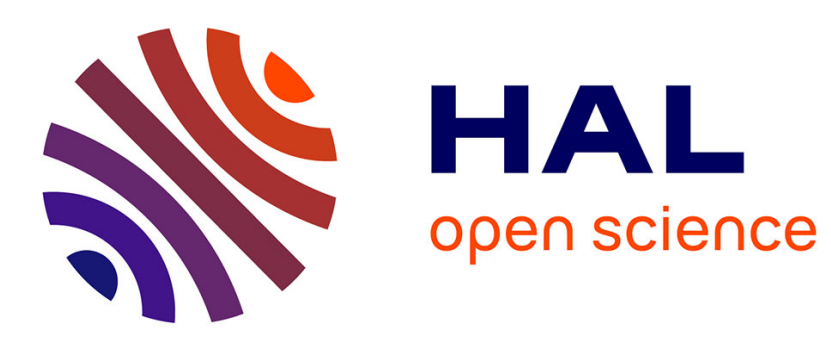

\title{
Applying physical acoustics to near-seafloor object echo-structure estimation
}

\author{
G. Kervern
}

\section{To cite this version:}

G. Kervern. Applying physical acoustics to near-seafloor object echo-structure estimation. Journal de Physique IV Proceedings, 1994, 04 (C5), pp.C5-1277-C5-1280. 10.1051/jp4:19945283 . jpa-00252995

\section{HAL Id: jpa-00252995 https://hal.science/jpa-00252995}

Submitted on 1 Jan 1994

HAL is a multi-disciplinary open access archive for the deposit and dissemination of scientific research documents, whether they are published or not. The documents may come from teaching and research institutions in France or abroad, or from public or private research centers.
L'archive ouverte pluridisciplinaire HAL, est destinée au dépôt et à la diffusion de documents scientifiques de niveau recherche, publiés ou non, émanant des établissements d'enseignement et de recherche français ou étrangers, des laboratoires publics ou privés. 


\title{
Applying physical acoustics to near-seafloor object echo-structure estimation
}

\author{
G. KERVERN
}

Thomson Sintra, Activités Sous-Marines, Route de Sainte Anne du Portziec, 29601 Brest cedex, France

\begin{abstract}
In HF sonars $(50 \mathrm{kHz}-500 \mathrm{kHz})$, the assumption of a perfect rigid body for targets of interest is often admitted and the ratio "wavelengthobject-length" leads to use physical acoustics theory to describe target-wave interactions. This has been done extensively for the determination of target strengths, especially for targets isolated in the water volume.

However, it is experimentally well-known that echoes of near-seafloor objects are different in amplitude and shape from echoes of the same objects in free water. Despite the presence of such boundaries (seasurface or seafloor), physical acoustics theory can still be used in this case as a first approximation.

In this paper, we propose a general method to rapidly evaluate strengths and structures of echoes from simple objects located near the seafloor and we present the validation of this target echo model by means of a specific experiment: a small scale experiment (1/5 scale) made around $200 \mathrm{kHz}$ in a large water test tank and using the sea surface as reflecting interface. The results obtained during this experiment well square with the envisaged target-wave interaction mechanism.
\end{abstract}

\section{INTRODUCTION}

In the area of HF $(50-500 \mathrm{kHz})$ seafloor imaging sonar, the seafloor generally participates to the echo formation process. The apparent result of this "seafloor effect" is often a rather unpredictable enhancement of the target strength and a complication of the echo shape. Therefore a better knowledge and understanding of the echo formation process, particularly when the seafloor is involved, is essential. This paper aims to contribule to improve this understanding in order to achieve better sonar designs.

\section{1 - ECHO MODELISATION}

\section{1 - Free space situation}

Let us consider a large object $(d » \lambda)$ with large radius of curvature $(\rho \geqslant \lambda)$. Physical acoustics theory gives us the classical following formula (Fresnel-Kirchhoff diffraction formula) for the received field $u_{r}$ :

$$
u_{r}=\alpha(\lambda) \cdot \frac{u_{0}}{j 2 \lambda R} \iint_{S} e^{-j k r(M)} \cdot\left(\cos \left[\theta_{1}(M)\right]+\cos \left[\theta_{2}(M)\right]\right) \cdot d s(M)
$$

where :. $u_{0}$ is the amplitude of the incident wave,

. $\alpha$ is the water absorption coefficient at the wavelength $\lambda$,

$. j^{2}=-1, k=2 \pi / \lambda$,

. $R$ is the mean target-receiver distance,

. $M$ is any point located on the illuminated part (S) of the target,
. ds (M) is the target surface element at $M$,

. $r(M)$ is the exact "transmitter-target point M-receiver" distance,

. $\theta_{1}(M)$ is the angle between the normal at $M$ and the incident wavevector $\vec{k}$,

$\theta_{2}(M)$ is the angle between the normal at $M$ and the direction towards the observation point.

\section{1 . 2 - Near seafloor situation}

Let us assume that the seafloor is reflecting (this assumption will be easily satisfied at low grazing angles below the limit refraction angle $\left(\leq 25^{\circ}\right)$ ) and flat. Compared with the free space situation, in the near seafloor situation different sound paths (i.e. geometrical specular paths associated to main target highlights or "bright zones") may exist from the sonar to the target and back to the sonar :
(1) Sonar $\rightarrow$
Target $\rightarrow \quad$ Sonar
(2) Sonar $\rightarrow$ Seafloor $\rightarrow$ Target
$\rightarrow \quad$ Sonar
$\rightarrow \quad$ : free space path
(3) Sonar $\rightarrow \quad$ Target $\rightarrow$
Seafioor $\rightarrow$ Sonar
$\rightarrow$
: one seafloor reflexion path
(4) Sonar $\rightarrow$ Seafloor $\rightarrow$ Target $\rightarrow$
Seafloor $\rightarrow$ Sonar
$\rightarrow$
: one seafloor reflexion path
(5) Sonar $\rightarrow$ Target $\rightarrow$
Seafloor $\rightarrow$ Target $\rightarrow$
Sonar
(6) Sonar $\rightarrow$ Target $\rightarrow$
Seafloor $\rightarrow$ Target $\rightarrow$
Seafloor $\rightarrow$ Target $\rightarrow$ Sonar
two seafloor reflexion path
(7) Etc. 
This rather intricate situation can be easily clarified taking into account the two following assertions :

$i$ : the paths involving seafloor reflections can be transformed in free space paths by "unfolding" the reflections as many times as necessary.

ii : the paths involving the targets several times should produce generally negligible echoes because the associated specular reflections on the seafloor will happen at large grazing angles where reflection coefficients are lower and decohering effects of surface irregularities higher. Therefore the only paths to retain are the first four paths previously mentioned.

If we accept these two assertions, the physical near seafloor situation can be split up in two virtual free space situations depicted in figure 1 :

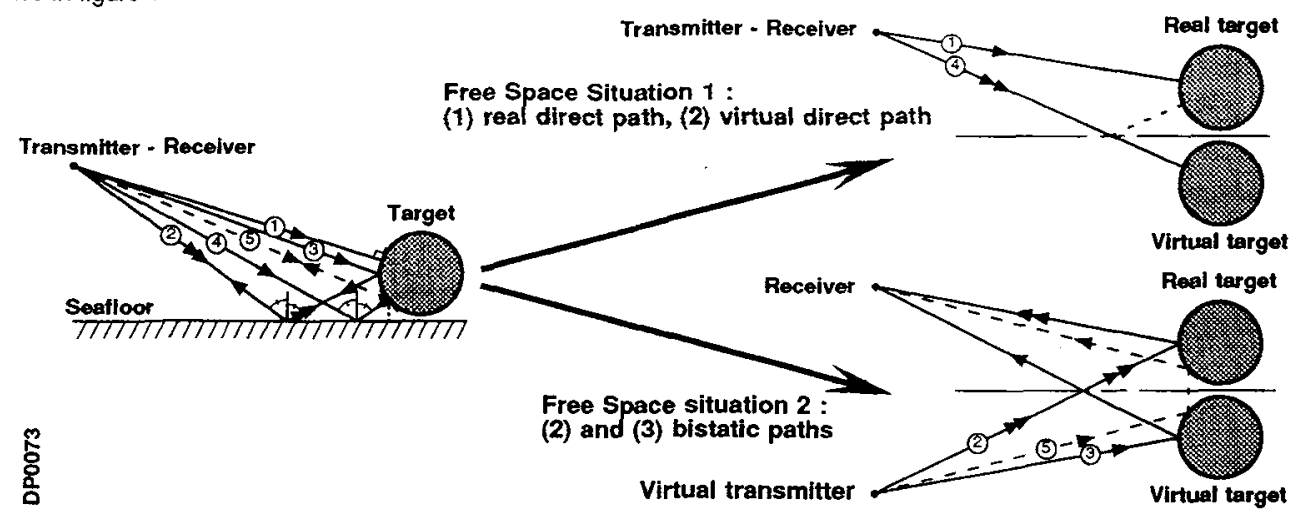

Figure 1 : Splitting up of physical near seafloor situation in two virtual free space situations

Free space situation 1 is a monostatic situation with a double target made up with the real target and its image, free space situation 2 is a bistatic situation with the same double target. Once these two free space situations are obtained, the standard physi$\mathrm{cal}$ acoustics method can be applied to estimate elementary echoes which will be further coherently added to build up the total target echo.

We have developed a software model based on the proposed echo estimation method and able to provide sonar designers with sonar simulated echoes and images of targets in their environment. Target and its images through the seafloor are discretized in elementary scattering surfaces and the elementary echoes coming from these elementary scatterers are coherently summed on each array transducer position with proper propagation phases. In this software the roughness of the seafloor is taken into account in the strengths of reflected echoes. A simulation result example of this software model is presented hereafter. Figure 2 shows the evolution of the echo-structure of a near vertical cylinder when its tilt angle varies from $+5^{\circ}$ to $-5^{\circ}$. The considered transmitted pulse is a compressed rectangular linear FM pulse with a $25 \mathrm{kHz}$ bandwidth and a 1 ms duration (BT = 25). In this simulation we can notice the presence of three particular tilt angles for which the ordinary complex echo-structure is reduced to a single strong peak.
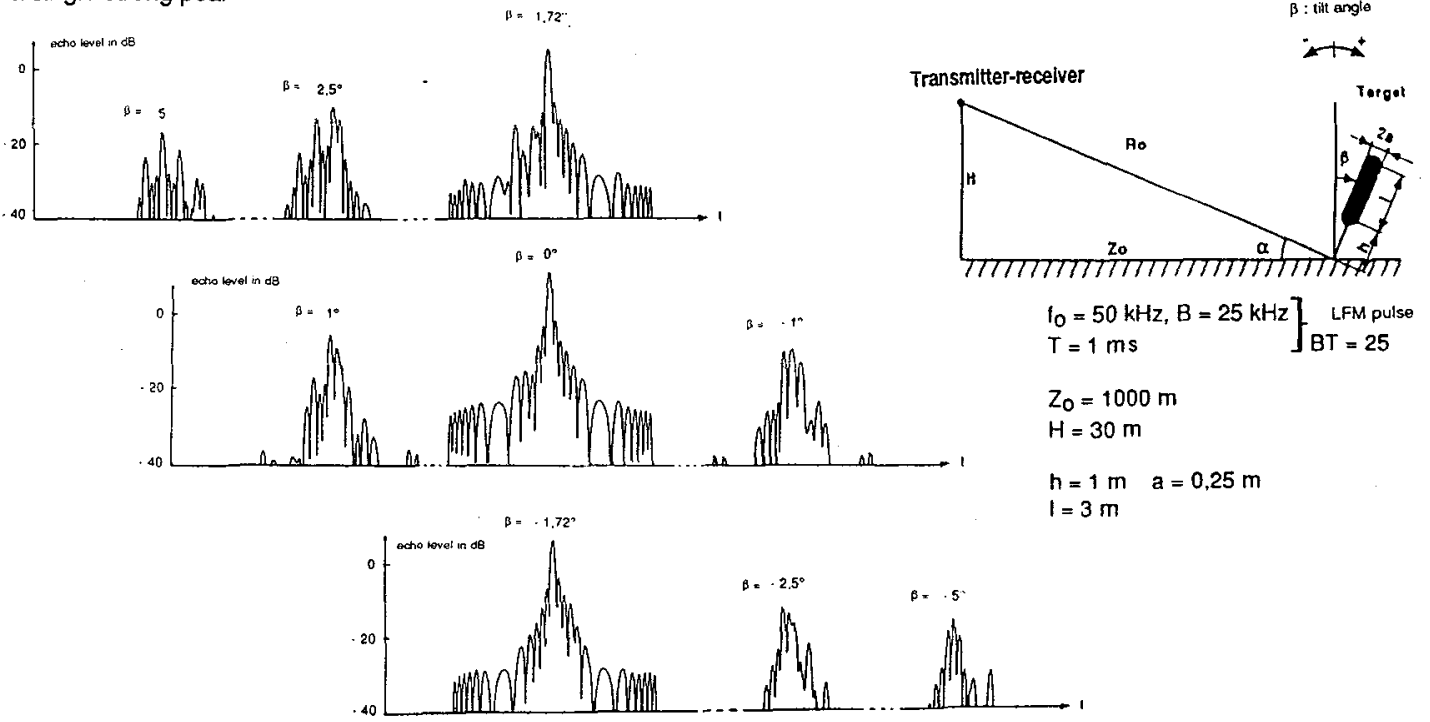

$$
\left.\begin{array}{l}
\mathrm{I}_{0}=50 \mathrm{kHz}, B=25 \mathrm{kHz} \\
T=1 \mathrm{~ms}
\end{array}\right] \begin{aligned}
& \text { LFM pulse } \\
& \mathrm{BT}_{0}=25 \\
& \mathrm{H}=30 \mathrm{~m}
\end{aligned}
$$$$
\mathrm{h}=1 \mathrm{~m} \quad \mathrm{a}=0,25 \mathrm{~m}
$$$$
\mathrm{I}=3 \mathrm{~m}
$$

\section{Figure 2 : Theoretical echo-structure evolution of a near vertical cylinder in function of its tilt angle}

Between these three tilt angles, the echo shape exhibits a more complicated structure often with three dominant peaks associated to highlights situated either at the top or at the bottom of the cylinder according to the tilt angle direction. 


\section{2-Assessment trials}

Briefly, the purpose of these trials is to check the validity of the assumptions made to develop our target echo model. These main assumptions read as follows:

1 - a perfectly rigid target-wave interaction,

2 - a strongly reflecting (because at low grazing angles we suppose to be below the critical angle of the water/sediment interface) and nearly flat interface,

3 - the predominance, among several acoustical paths, of the first four paths (ct. part 1, figure 1) in the echo formation process.

Assumptions 1 and 3 have been validated by means of small scale $(=1 / 5)$ trials carried out at frequencies around $200 \mathrm{kHz}$ in a large water test tank (a former dock yard). Assumptions 2 and partially 3 are now under consideration and will be possibly corrected by full size trials in a deep water site at frequencies between $30 \mathrm{kHz}$ and $100 \mathrm{kHz}$.

A schematic description of the experimental arrangement of small scale trials is given figure 3 . In this experiment the seafloor interface is simulated by the air-water interface.

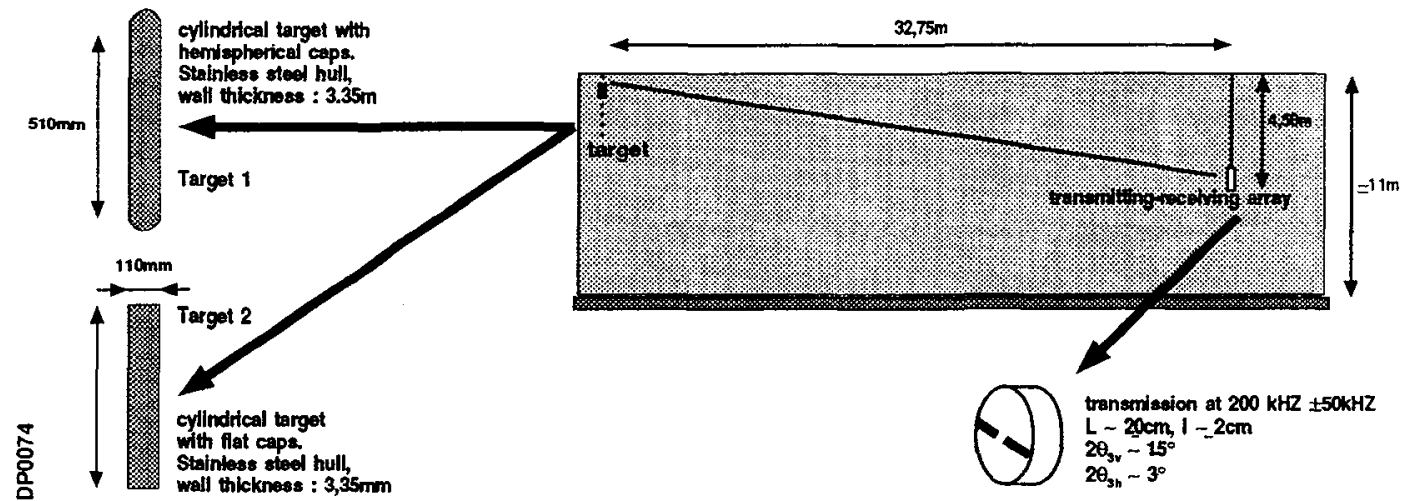

Figure 3 : Small scale experiment arrangement.

The experimental results given by these water test tank trials have generally leaded to a very good verification of the targetwave interaction process for a object situated near a reflecting interface.

(1). First presented results (figure 4, last page) deal with a cylindrical target with hemispherical caps. The three particular tilt angles for which the echo is reduced to a single strong peak appear clearly:

$\beta_{1}=7.02^{\circ}, \beta_{2}=0^{\circ} . \beta_{3}=-7.59^{\circ}$ with $\operatorname{Arctg}\left(\frac{H}{z_{0}}\right)=\operatorname{Arctg}\left(\frac{4.375}{32.75}\right) \approx 7.60^{\circ} \approx \beta_{1} \approx-\beta_{3}$

(2) - Second presented results (figure 4, last page) are related to a cylindrical target with flat extremities and compares experimental echoes with simulated ones. Despite the presence of a sharp edge in the target shape, the agreement between experiment and simulation remains fairly good.

\section{CONCLUSION}

Our target model assumes a target situated near the seafloor and observed at low grazing angles, a perfectly rigid target-wave interaction and the dominance of four particular acoustical paths among the numerous possible paths when a strongly reflecting interface is present. A first series of small-scale experiments using the water surface as interface has validated the chosen target-wave interaction and the effective dominance of the four retained acoustical paths (an estimation of $75 \%$, at least, of "simulation efficiency" of our target model software could be proposed). A second series of full-scale trials (not described here) has confirmed the dominance of our four retained acoustical paths in the echo formation mechanism when reflections occur on a real sea bed. These last in situ measurements made on a sea bed of very soft mud need to be completed. However, the entire validation experiments already made allow us to use this target echo model software as a front-end for further realistic sonar simulation work.

\section{Acknowledgment}

This work was carried out with the support of Groupe d'Etudes Sous-Marines de l'Atlantique (GESMA, 29240 Brest Naval, France) within the framework of the Franco-English collaboration on remote Mine Hunting Systems. The author would like to thank particulary F. Charles (Thomson Sintra ASM), A. Salaün (GESMA) and S. Tanguy (GESMA) for their hetpful participations in sottware writing and experiment planning.

\section{References}

(1) Y. Rocard, "Dynamique générale des vibrations", Masson 3rd Edition, 1960.

(2) M. Born and E. Wolf, "Principles of optics", Pergamon Press 6th Edition, 1986. 


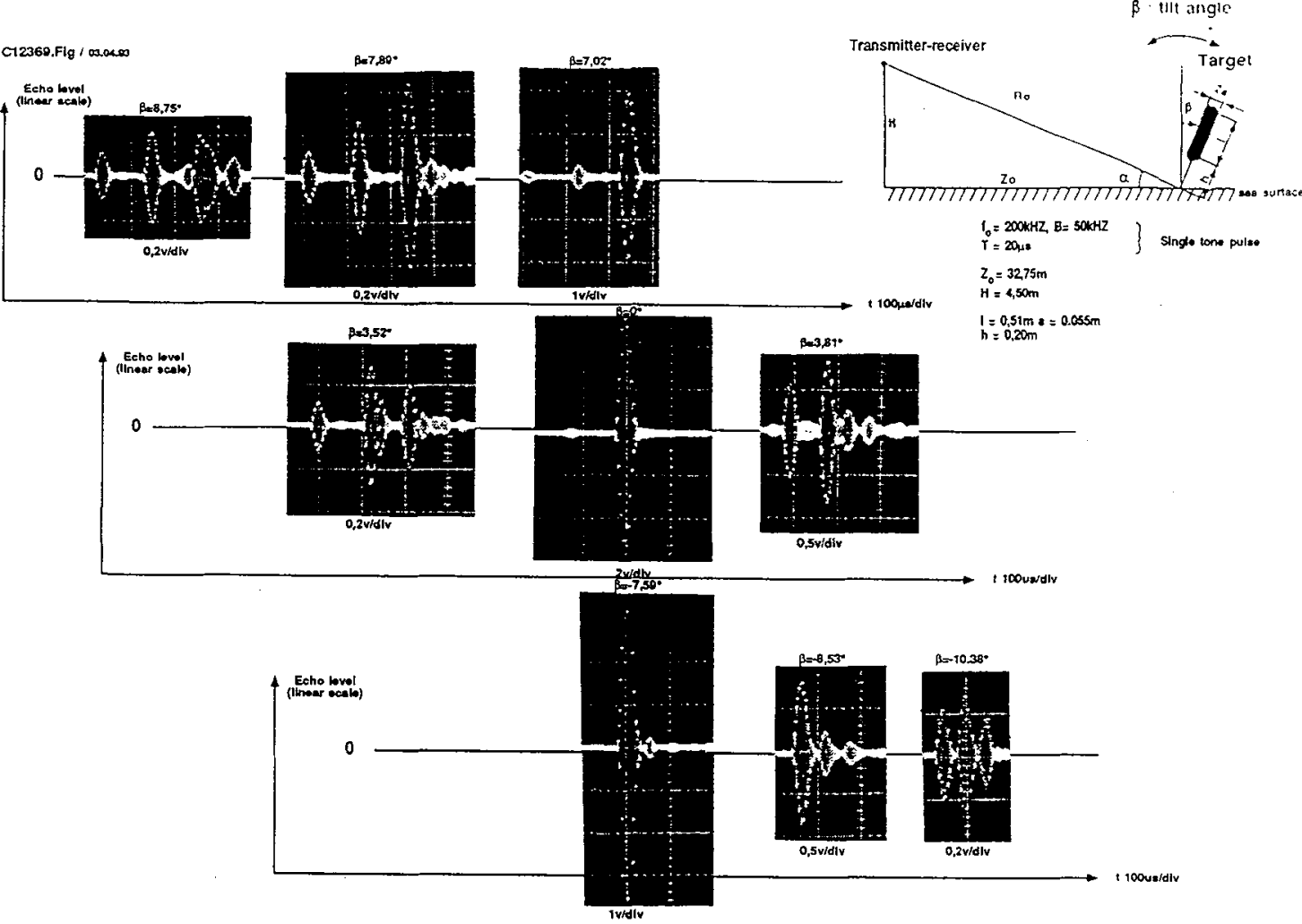

Figure 4 : Experimental echo-structure evolution of a near vertical cylinder in function of its tilt angle (single tone pulse, target 1/figure 3: near vertical cylinder with hemispherical caps).

EXPERIMENTATION
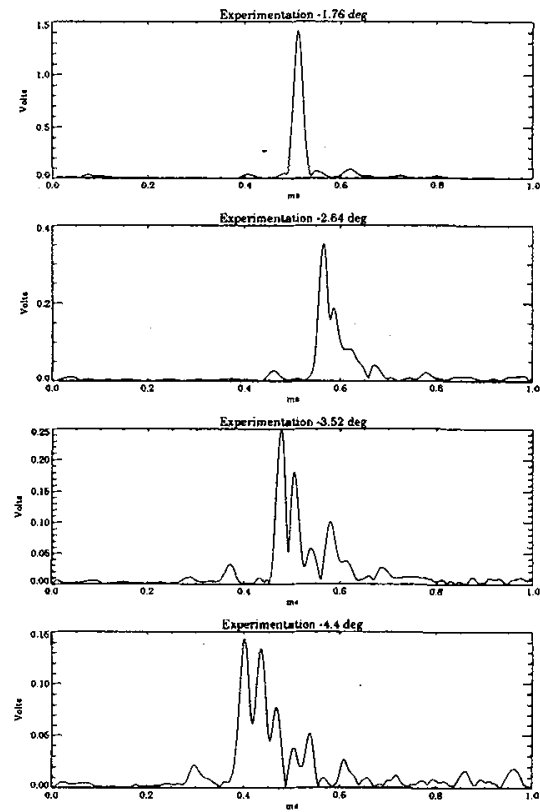

SIMULATION

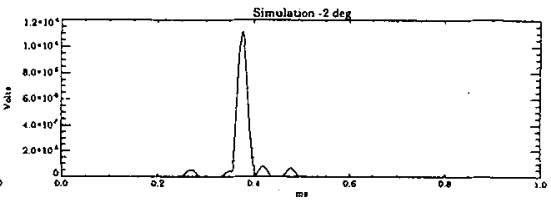

Simulation -2.75 der
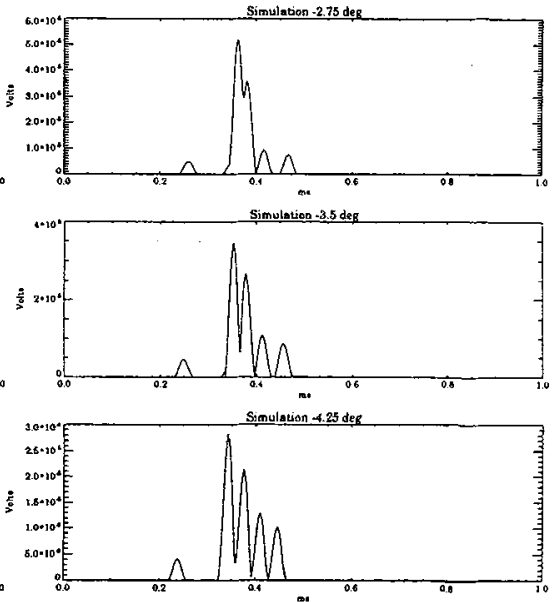

Figure 5 : Comparison between experimental and simulated echoes for different tilt angles (target 2/figure 3: near vertical cylinder with flat extremities). 